\title{
INTERDIÇÃO SOCIAL EM USOS DE SER E ASSUMIR COM OBJETO ZERO NO CONTEXTO DA HOMOSSEXUALIDADE
}

\author{
Rafahel Jean Parintins Lima
}

\begin{abstract}
RESUMO
Este estudo analisa a interpretação de usos dos verbos "ser" e "assumir" enquanto candidatos a Construçóes de Objeto Interdito (COI) quando esses verbos são usados como transitivos em enunciados inseridos no tópico discursivo homossexualidade. Os resultados revelam a influência de aspectos interacionais para a avaliação da transitividade dos usos verbais.
\end{abstract}

PALAVRAS-CHAVE: transitividade; tópico; homossexualidade.

\section{Introdução}

Esta investigação tem como objetivo analisar a interpretação de usos dos verbos "ser" e "assumir" enquanto candidatos a Construçôes de Objeto Interdito (doravante COI) quando esses verbos são usados como transitivos em construçóes de enunciados inseridos no tópico discursivo da homossexualidade, isto é, quando esses usos verbais são interpretáveis como correspondendo a "ser homossexual/gay/viado/etc." e "assumir a homossexualidade/ser homossexual/etc.”. Os dados analisados foram coletados através de entrevistas de base experimental. Para analisar os dados, utilizaremos a noção de tópico discursivo, que consiste em uma noção textual macrossemântica formada pela construção relacional de um "conjunto de referentes explícitos ou inferíveis concernentes entre si e em relevância num determinado ponto da mensagem" (JUBRAN, 1992, p. 136), que constituem o aboutness textual, o construto discursivo 
"aquilo sobre o que se fala". Assim, utilizamos conhecimentos provenientes dos estudos das Construçóes Gramaticais e aqueles provenientes das investigaçóes sobre a organização textual-discursiva. Os dados foram interpretados como sendo a exemplificação da indicação de que as interdiçóes sociais, em forma de enquadres de rompimento de regra de conduta social (BRONZATO, 2009) são interpretaçōes preferidas do interlocutor diante da produção de enunciados com os verbos "ser" e "assumir" em fórmulas sintáticas coincidentes com as das Construções de Objeto Interdito (COI), mesmo quando o tópico discursivo da homossexualidade não é oferecido. O tópico, no entanto, desempenha grande papel na especificação referencial da entidade semântica dissimulada pelo apagamento do objeto verbal: assim, a noção de transitividade passa também por critérios interacionais. Sinalizamos, ao final, que as ocorrências exemplificadas configuram tabus e preconceitos sociolinguísticos.

\section{Construçóes de Objeto Interdito}

As COI (Construções de Objeto Interdito) aqui analisadas são Construçôes do português brasileiro descritas em Bronzato $(2000 ; 2009)$ a partir da perspectiva da Gramática de Construçóes e considerando também as noçóes interacionais de enquadre e de polidez. Uma característica dessas construçóes é o zero no lugar do objeto de predicadores verbais que, do ponto de vista de sua valência básica, são considerados transitivos. A configuração sintática das COI se formaliza em [SN V Ø (SP)], em que SN é um sintagma nominal [+humano], $V$ um verbo, Ø é o complemento verbal nulo e SP é outro complemento, também [+humano], que pode ou não aparecer. O que especifica as COI é o fato de, segundo Bronzato (2009), o objeto zero ser fruto da influência da polidez positiva (proteçáo da face dos interlocutores) em relação a um objeto relacionado a um modelo cognitivo idealizado ${ }^{1}$ de interdiçấo social.

\footnotetext{
Noção de Lakoff (1987) recuperada por Bronzato (2009). Modelos cognitivos idealizados (MCIs) sáo estruturas por meio das quais organizamos nosso conhecimento. As ideias sobre modelos cognitivos de que Lakoff (1987) lança mão "foram desenvolvidas a partir de quatro fontes: a semântica de frames de Fillmore (1982), a teoria da metáfora e da metonímia de Lakoff e Johnson (1980), a gramática cognitiva de Langacker (1986) e a teoria dos espaços mentais de Fauconnier (1985) (...). Cada MCI é um conjunto complexo estruturado, uma gestalt, que usa quatro tipos de princípios estruturantes:

- estrutura proposicional, como nos frames de Fillmore;
} 
Essa construção indicia, assim, rompimento de regra de conduta social. Exemplos: “fazer (sexo)", “dar (o cu)", "cheirar (cocaína)", "fumar (maconha)”, etc.

As COI não instauram esse enquadre de rompimento de regra de conduta apenas por conta da fórmula sintática per se: nesta investigação, analisamos a colaboração do tópico discursivo para a instauração desse enquadre, através da construção inferencial e referencial da entidade semântico-discursiva que está por trás do zero $(\varnothing)$ do objeto. Essas construçóes resultam, em termos formais, em uma destransitivização. No entanto, o zero do objeto não é semanticamente vazio porque o referente envolvido é inferível a partir de conhecimentos socialmente compartilhados.

Consideramos, neste estudo, que esse tipo de construção é o caso contemporâneo dos verbos "ser" e "assumir" quando usados no sentido de "ser homossexual", "ser gay", "ser viado", etc. ${ }^{2}$ e no de "assumir a homossexualidade" ou "assumir ser homossexual", etc., uma vez que os itens lexicais potencialmente ocupantes da categoria de objetos nesses verbos podem não aparecer, ficando apenas subentendidos. Sugerimos também que a interdição social, assim, se faz mais sobre a entidade referencial semântico-discursiva, que é subentendida no zero ocupante da categoria de objeto verbal, do que sobre o objeto verbal em si, pois este constitui apenas a função ou categoria gramatical sobre a qual reverbera, na forma do item zero, a interdição referencial. Faremos, assim, mais abaixo, para que fique terminologicamente clara, a diferenciação entre categoria gramatical e entidade referida.

Como forma de visualizarmos como se comportam outros tipos de predicadores verbais que não sejam o verbo "ser", quando transitivo, e "assumir", que costuma ser tanto transitivo quanto pronominal (se acompanhado do pronome "se" no infinitivo), apresentaremos também dados com o verbo "usar", também transitivo ou pronominal. Os verbos "ser" e "assumir", quando destransitivizados, restringem seus objetos a entidades particulares. Bronzato (2009, p. 77) relata que esses verbos restringem "o conjunto de enti-

- estrutura do esquema-imagem, como na gramática cognitiva de Langacker;

- mapeamentos metafóricos, como descrito por Lakoff e Johnson;

- mapeamentos metonímicos, como descrito por Lakoff e Johnson.

Cada MCI, quando usado, estrutura um espaço mental, como descrito por Fauconnier" (LAFOFF, 1987, p. 68, tradução nossa).

2 Um exemplo é o título brasileiro Será que ele é? do filme americano In \& Out de 1998, cujo enredo se constrói em torno da dúvida que paira sobre a sexualidade do protagonista. 
dades capazes de ocupar o espaço referencial correspondente ao objeto direto", revelando certa lexicalidade dessa construção verbal. Veremos que o mesmo acontece com o verbo "usar", apesar de essa restrição ser menor, isto é, "usar" consiste em um verbo menos produtivo na construção de Objetos Interditos.

\section{Categoria gramatical e entidade referencial}

A categoria gramatical diz respeito à classificação formal que recebe o item linguístico ocorrente. A categoria gramatical é o estatuto formal do item linguístico nos termos da organizaçáo gramatical. Ela pode ser ocupada por um item lexical, por uma sentença ou por zero. A entidade referencial, ou referente, por sua vez, tem um caráter semântico-discursivo e, de uma forma geral, pode ser "ativada" através de um item lexical, que ocupa, assim, uma categoria gramatical, seja ela o objeto verbal ou não. Essa entidade referencial, ou semântico-discursiva, pode também aparecer implícita no texto.

No caso de verbos transitivos, podem instalar-se diferentes itens lexicais na categoria de objeto, ou mesmo sentenças inteiras (com valor de objeto), ou o zero. Geralmente se considera que esta última situação, isto é, o zero como objeto de usos verbais transitivos, só ocorre, na linguagem, no caso de elipse anafórica. Como veremos, no entanto, quando se consideram aspectos interacionais, o zero em usos transitivos pode ocorrer com ou sem elipse anafórica. No caso de anáfora, o fenômeno se assemelha, segundo Bronzato (2009), ao que Marcuschi (2000) chama de anáfora sem antecedente textual explícito (anáfora esquemática).

Esses usos transitivos são o caso das COI com os usos verbais de "ser" e "assumir" com objeto zero, com o sentido de, por exemplo, "ser homossexual" e "assumir a homossexualidade", aqui analisados. Chamamos esses usos de casos transitivos a partir de um ponto de vista sintático-semântico. $\mathrm{O}$ item ou o zero ocorrentes que ocupam a posiçáo de objeto verbal, nesse caso, contribuem para a construçáo do sentido textual, principalmente através da construção referencial de uma entidade semântica.

\section{Método e análises}

A fim de problematizarmos o estudo em torno das COI, de acordo com 
o nosso objetivo de pesquisa, realizamos duas formas de coleta de dados, apresentadas abaixo como Dados I e Dados II, respectivamente. Ambos os Dados tiveram o objetivo de investigar a interpretação da transitividade e de referentes inferidos a partir da produção de construções verbais com verbos considerados transitivos e ocorrência de objeto zero. Os Dados I consistem em um experimento introdutório, com a especificidade de visualizar como funciona um uso verbal que não aquele com "ser" e "assumir". Os Dados II, por sua vez, foram centrados especificamente nestes últimos usos verbais. Em ambos os procedimentos, trabalhou-se com o perfil de informantes homens homossexuais, residentes em Campinas (SP), com Ensino Superior e na faixa etária de 23-29 anos.

\section{Dados I: uso verbal com "usar” sem demanda direta de tópico}

Foi apresentado, individualmente, para 6 (seis) informantes homens, de 23 a 29 anos de idade, um folder (em Anexo) sobre o uso de drogas ilícitas elaborado pela Coordenadoria de Serviços Sociais da UNICAMP, em cuja capa se lia apenas "Ei! Você usa?". Foi perguntado aos informantes sobre que tema tratava o folder, isto é, sua proposta tópica, sem que eles o abrissem para saber sobre o que ele (o folder) tratava de fato. 2 (dois) informantes responderam que o folder se referia ao uso de drogas e os outros 4 (quatro) disseram que se referia ao uso de preservativos.

Ambas as hipóteses levantadas se referem a tabus sociais: uso de drogas ilícitas e sexo. O levantamento de apenas duas possibilidades parece indicar a tentativa de mobilizar e de centrar-se principalmente nas interdiçóes sociais para contextualizar os usos verbais transitivos de objeto zero, como o uso verbal de "usar", nesse caso. Aqui, sem que os informantes possam pedir um tópico discursivo norteador, a hipótese do rompimento de conduta é uma inferência preferida.

No caso do folder, o objeto zero pode ser explicado pelo fato de se tratar de uma catáfora: nos textos da parte interna do folder, a entidade referida se esclareceria. No entanto, a preferência por enquadres de rompimento de conduta indica que o apagamento da entidade não ocorre apenas por ter a função de criar expectativas no leitor, e sim porque ele, o referente, está submetido a uma interdição social. É necessário notar que é tomado como tácito o co- 
nhecimento de que os usos verbais com "usar", nos dados obtidos, precisam de complemento, porque os informantes aceitaram sem muita estranheza a ausência de complemento, mesmo que esse uso verbal seja considerado como transitivo. Essa interpretação é possível porque os informantes responderam (levantando apenas duas hipóteses interpretativas) sem questionar a plausibilidade dos dizeres da capa do folder. Isso acontece, em parte, porque, no caso de catáforas, a transitividade do uso verbal é mais evidente, já que uma das funçôes é justamente criar expectativas em relação a uma entidade abstraída do objeto zero e construída contextualmente. Os Dados II, por sua vez, analisam casos em que os enunciados não configuram catáfora. Isso ocorre, no nosso estudo, com alguns usos de "ser" e "assumir".

\section{Dados II: usos verbais com "ser" e "assumir" com demanda de tó- pico e instauraçáo de homossexualidade}

Foram entrevistados 3 (três) homens de 23, 26 e 29 anos, respectivamente. O protocolo foi elaborado para avaliar o reconhecimento de formas como sendo Construçôes de Objeto Interdito através da identificação da entidade a que se referiria o item lexical na posição de objeto, sem, a princípio, se instaurar claramente um tópico direcionador. A identificação explícita de uma entidade referencial (por exemplo, entidade referencial um homossexual ${ }^{3}$, para usos verbais com "ser", e ser homossexual, para usos verbais com "assumir") indica a transitividade do uso verbal e a identificação da necessidade de um complemento indica se há objeto e se, assim, neste caso, há interdição da entidade apagada. Isto posto, a entrevista seguiu o seguinte protocolo, observadas a ordem seguinte de perguntas e as condições de sua execução, descritas entre parênteses abaixo:

Q1: Você é?

Q1.1: O que você é? (apenas no caso em que o informante responder "Sou.", ou equivalente, a Q1).

3 No caso dos usos verbais com "ser", quando são transitivos, requerem um objeto que abrigue um item referencial que pode indicar uma entidade em relação categorial. Por exemplo, quando dizemos "Ele é homossexual", estamos dizendo que ele é um homossexual, isto é, um exemplar da categoria dos homossexuais. Ao qualificarmos a entidade como sendo "homossexual", estamos enfatizando sua categoria, a dos homossexuais, para identificar essa entidade. Esse tipo de uso de "ser" tem, portanto, função categorizadora, pois aloca a entidade em dada categoria de referentes. 
Q1.2: Falando de homossexualidade, você é? (Apenas no caso em que o informante perguntar "sou o quê?" frente a Q1).

Q2: Você já assumiu para alguém?

Q2.1: O que você assumiu? (apenas no caso em que o informante responder "Sim." a Q2)

Q2.2: Falando de homossexualidade, você já assumiu para alguém? (apenas no caso em que o informante perguntar "assumir o quê?" frente a Q2)

Assim, observemos os dados que obtivemos a partir da aplicação desse protocolo, que procurou prever algumas possibilidades de respostas.

Informante I: 23 anos, mestrando em Geografia, natural de São Pedro (SP)

Q1:Você é?

$\mathrm{R} 1:$ É o quê?

Q1.2: Falando de homossexualidade, você é?

R1.2: Eu prefiro me... não me rotular.

Q2: Você já assumiu para alguém?

R2: Bom, se eu não me rotulei, não seria necessariamente um "assumir" pra alguém. Eu tive relacionamentos homoafetivos ou homossexuais... e, nesses, algumas pessoas sabem.

O que podemos afirmar dos dados obtidos com o informante I é que ele acusa a transitividade do uso verbal com "ser" ao responder com a pergunta "É o quê?”. Embora a entidade referencial continue implícita na resposta R1.2, quando o tópico da homossexualidade é indicado em Q1.2, ele, o referente, é implicitamente reconhecido, já que é qualificado (como "rótulo"). Por fim, embora questione os termos da pergunta Q1.2 (e, por essa razão, não houve sentido em realizar a pergunta Q2.1), o informante a responde, segundo suas crenças, inferindo assim um tópico discursivo específico e a transitividade do uso verbal com "assumir", apesar de continuar mantendo implícita a entidade referencial. 
Observemos agora o caso do informante II:

Informante II: 26 anos, funcionário público, licenciado em Matemática, de Mi$\underline{\text { rassol (SP) }}$

Q1: Você é?

R1: Se en sou? Sou.

Q1.1: O que que você é?

R1.1: Eu sou gay, eu sou homem, eu sou matemático, depende do que você quer saber que eu sou.

Q2: Você já assumiu para alguém?

R2: É vago, né? Porque você pode assumir qualquer coisa. Pode assumir um filho, pode assumir sua homossexualidade...

Q2.2: Falando de homossexualidade, você já assumiu para alguém? R2.2: Já. Para uma amiga, por exemplo.

No caso do informante II, há a explicitação de entidades que são listadas em R1.1. Ao responder em R1.1, ele nomeia, em série, as entidades possíveis, relatando, ao dizer "depende do que você quer saber", que o aparecimento lexical de dada entidade referencial depende do tópico discursivo em jogo. Na pergunta Q2, o informante se mantém coerente com a resposta dada em R1.1, já que novamente relativiza a referência: o uso verbal de "assumir" pode implicar diferentes referentes, um filho, a homossexualidade, etc. Por fim, em Q2.2, é-lhe especificado o tópico discursivo "homossexualidade" ("Falando de homossexualidade,...”). Diante dessa determinação tópica, assim, o informante demonstra inferir um item referencial na posiçáo de objeto do uso verbal de "assumir", ao responder a última pergunta de forma afirmativa: "Já. Para uma amiga, por exemplo".

Informante III: 29 anos, professor de Filosofia na rede estadual, licenciado em Filosofia, natural de Campinas (SP) 
Q1: Você é?

R1: Bicha? Sou... Sobre o quê cê tá falando?

Q2: Você já assumiu para alguém?

R2: Pra todo mundo!

Q2.1: O que você assumiu?

R2.1: A bichice!

Neste dado, o informante III, ao responder "Bicha?", demonstra levantar uma hipótese sobre o que a pergunta Q1 trata, inferindo um tópico discursivo e, assim, a possibilidade de o referente implícito ser "uma bicha", uma vez que ele responde "Sou", mesmo que, ao dizer "Sobre o quê cê tá falando?", deixe entrever a necessidade de uma explicitude tópica e a incerteza provocada pela possível falta de um referente explícito. A pergunta Q2, "Você já assumiu para alguém?” é respondida tomando-se a primeira inferência como válida, já que o informante responde afirmativamente à pergunta. Em Q2.1, por fim, é-lhe demandado o referente implícito, no par pergunta-resposta Q2/R2. Enfim, ao responder que já assumiu a "bichice" e considerando a forma com que respondeu às outras perguntas, podemos dizer que o informante III especifica um tópico (homossexualidade) com ligeireza e, também, em R2, o referente em jogo.

\section{Gramática, sentido e discurso}

Considerando as interpretaçóes dos Dados I e II, observa-se, por um lado, nos Dados I, o levantamento de hipóteses interpretativas (drogas ou preservativos) que se referem a itens referenciais interditos, frente ao uso verbal de "usar" sem objeto ocupado. Esse levantamento de hipóteses se dá sem a ajuda do tópico discursivo. Por outro lado, nos Dados II, nota-se o papel do tópico discursivo enquanto mediador da interpretação das construções verbais como sendo COI. Isso indica que, diante da ausência de tópicos discursivos precisos que delimitem as possibilidades de sentido (como no caso da leitura da capa de um folder em que se lê apenas "Você usa?"), o interlocutor lança mão da hipótese de rompimento de conduta, de interdição, para o caso de usos verbais que são passíveis de ser interpretados como de Objeto Interdito. No caso em 
que os tópicos discursivos são recuperáveis, como no caso da conversação, em que o produtor das construçôes verbais está acessível, lança-se mão dessa possibilidade de recuperação do sentido, isto é, indaga-se por um tópico mais preciso para a obtenção da entidade semântica, ou indaga-se diretamente por um item referencial, para que a interpretação seja a mais adequada possível. O resultado disso é um reenquadramento interacional construído processualmente pelos sujeitos.

A interpretação da transitividade de que estamos tratando aqui, em vista de nossos resultados, extrapola aspectos estritamente sintático-semânticos, passando a se relacionar também com aspectos interacionais. Como podemos perceber através da apresentação das análises, nem sempre as formas apresentadas como [SN1 V Ø (SP)] ("Você é?", "Você assumiu?") são reconhecidas como COI, uma vez que os informantes necessitam, muitas vezes, da instauração de um tópico preciso.

Pode existir em nossos informantes, uma tendência a interpretar as Construçôes disponibilizadas como se referindo à homossexualidade, reconhecendo, assim, a interdição social nelas presente: em dois dos informantes, não foi necessária a instauração imediata do tópico discursivo da homossexualidade para que falassem "sou gay" ou "sou bicha". Isso pode ser devido, em parte, ao recorte dos perfis dos informantes (todos são homossexuais). Isso significa que também pode estar em jogo a própria identidade social do falante ao se deparar com possíveis COI. Além disso, isso pode se dever também, a depender do tópico (aspecto discursivo) e da identidade (aspecto social) envolvidos, tratando-se de COI, à relativa facilidade com que as COI podem ser "identificadas" como tais. Melhor dizendo, esses usos podem ser facilmente identificados como construçóes que envolvem entidades interditas, embora nem sempre essa interpretação interacional ocorra. A transitividade discursiva das construçóes apresentadas, a ocorrência de zero no objeto verbal, o enquadre de rompimento de conduta, isto é, a interdição social da entidade, foram interpretados como tais sem muitos titubeios.

Por fim, é necessário dizer que, como o objeto está presente, embora em forma de zero, não é ele que está interdito. A interdição é dirigida, assim, mais diretamente à entidade referencial e não ao objeto, que é uma categoria gramatical. As COI podem, assim, ser definidas como construçóes verbais em que o item ocupante do lugar de objeto não aparece, por conta da interdição 
do referente. Formalmente, nesse caso, o uso verbal possui uma ocorrência intransitiva, embora sua transitividade gramatical seja recuperável pela demanda sintática, semântica, discursiva e interacional que ele instaura. Essa constatação reforça a ideia de que a destransitivização presente em COI é apenas formal.

\section{Consideraçóes finais: aspectos sociolinguísticos}

Discutidos os resultados deste estudo, resta arrolar alguns afinamentos metodológicos para o futuro e algumas implicaçóes. Um desses afinamentos é investigar um número maior de informantes e utilizar dados quantitativos para verificar nossos resultados, abarcando, assim, informantes com outros perfis sociais.

Como dissemos um pouco mais acima, os usos verbais possuem particularidades em relação à sua interpretabilidade como COI. As interdiçôes sociais foram levantadas pelos informantes como hipóteses de tópicos discursivos para que a expectativa anafórica fosse justificada e para que o uso verbal com "usar" tivesse um objeto. Isso ocorreu mesmo considerando um uso verbal ("usar") cuja utilização em referências a interdiçóes sociais não é muito conhecida. Assim, é possível efetuar também um estudo comparativo, neste sentido, dos usos verbais dos verbos "usar", "ser", "assumir", e outros, quanto à sua interpretabilidade enquanto COI.

Quanto às implicaçóes, sugerimos que as construçóes de "ser" e "assumir" com Objeto Interdito são um tipo de tabu linguístico, isto é, um tipo de interdição sociolinguística: algo de que se lança mão para não se usar certos itens lexicais. Nesse caso, no entanto, a interdição não se faz sobre itens lexicais em si, mas a certas entidades semântico-discursivas. Esse arrazoado toma uma perspectiva diferente de tabu, já que os tabus linguísticos costumam ser tratados de forma independente dos usos verbais, isto é, sem serem relacionados às propriedades sintáticas, já que se restringiriam a questóes estritamente lexicais (cf. ORSI, 2011; ALMEIDA, 2007; SHADID, 2011; RICHTER; ISQUERDO, 2009); enfim, eles não costumam ser tratados como interdiçóes semântico-discursivas que têm reverberação léxico-gramatical. Aparentemente noçóes diferentes, os tabus linguísticos estão relacionados aos tabus sociais. Segundo Bronzato (2009, p. 79, grifos da autora): 
No Brasil, como talvez em qualquer sociedade, os assuntos considerados tabus sociais submetem-se, na interação verbal, a algumas imposiçôes socioculturais, dadas sob a forma de instruçôes pragmáticas, isto é, sob a forma de regras de adequação da linguagem à situação. A primeira delas é a requisição de serem evitados, especialmente em determinados contextos. A segunda é a de serem dissimulados, e a terceira prática de encobrimento dos tabus sociais na interação é o eufemismo.

Assim, estamos lidando, aqui, com casos em que os sentidos são dissimulados, mas não evitados. Baseando-se em Orsi (2011), a produção de COI pode ser considerada também um tipo de preconceito sociolinguístico, justamente por ser um tabu. Diferentemente, no entanto, daquele preconceito que decorre de uma atitude perante uma variedade sociolinguística. No caso das COI, trata-se de uma manobra de polidez (BRONZATO, 2009) e de um preconceito sociolinguístico que afeta o próprio uso do falante, com motivação ideológica e de forma pouco consciente, visto que as COI compóem um fenômeno linguístico bastante produtivo no português contemporâneo (BRONZATO, 2009).

Os interlocutores firmam o pacto de que não é necessário (ou melhor, é proibido) que a entidade semântico-discursiva (no caso, a homossexualidade de alguém ou a categorização social de alguém como homossexual) se explicite, seja visível. Levando em consideração que a polidez é um processo cultural, o fato de os processos de que estamos tratando configurarem-se em uma manobra de polidez indica que a interdição social se infiltra na cultura de usos, e que, portanto, a ideologia pode ser fortemente incorporada pelos atos de polidez. Esta investigação colabora, assim, para a melhor compreensão da influência da sociedade na língua, em vista das implicaçóes citadas, que concernem aos aspectos ideológicos da linguagem.

\section{Referências}

ALMEIDA, Laura de. Os tabus linguísticos e a abordagem da diversidade cultural no ensino de língua portuguesa. Estudos Linguisticos, 36 (2): 139-145, São Paulo, 2007. 
BRONZATO, Lucilene Hotz. A abordagem sociocognitivista da construção de destransitivização: o enquadre da interdição. 2000. 115f. Dissertação (Mestrado em Letras-Linguística) - Instituto de Ciências Humanas e de Letras, Universidade Federal de Juiz de Fora, Juiz de Fora, 2000.

. O enquadre gramatical da interdição ou "a bom entendedor meia palavra basta”. In: MIRANDA, Neusa Salim; SALOMÃO, Margarida. (Org.). Construçóes do Português do Brasil: da gramática ao discurso. Belo Horizonte: Ed. UFMG, 2009, p. 76.

FAUCONNIER, Gilles. Mental Spaces. Cambridge, Mass.: MIT Press, 1985.

FILLMORE, Charles. Frame Semantics. In: Linguistic Society of Korea, ed., Linguistics in the Morning Calm, Seoul: Hanshin, 1982, pp. 111-138.

JUBRAN, Clélia Cândica Abreu Spinardi et al. Organização tópica da conversação. In: ILARI, R. (Org.). Gramática do português falado. Campinas, SP: Ed. da UNICAMP, 1992, vol. II, p. 322.

LAKOFF, George. Women, fire, and dangerous things: what categories reveal about the mind. Chicago: The University of Chicago Press, 1987.

; JOHNSON, Mark. Metaphors we live by. Chicago: University of Chicago Press, 1980.

LANGACKER, Ronald. Foundations of Cognitive Grammar, vol. 1. Stanford: Stanford University Press, 1986.

MARCUSCHI, Luiz Antônio. Aspectos da progressão referencial na fala e na escrita no português brasileiro. In: GÄRTNER, Eberhard; HUNDT, Christine; SCHRÖNBERGER, Axel (Org.). Estudos de linguistica textual do português. Frankfurt am Main: TFM, 2000, p. 79.

ORSI, Vivian. Tabu e preconceito linguístico. ReVEL, 9 (17): 334-348, 2011.

RICHTER, Lisiane da Silva de Arruda; ISQUERDO, Aparecida Negri. Mitos e tabus linguisticos: contribuiçóes do Projeto ALIB, 2009, http://www.propp. ufms.br/gestor/titan.php?target=openFile\&fileId=615, 11/12/2012.

SHADID, Annette Calvo. Sobre el tabú, el tabú lingüístico y su estado de la cuestión. Káñina, Rev. Artes y Letras, Univ. Costa Rica, 35 (2): 121-145, Costa Rica, 2011. 


\title{
INTERDICT IN THE USES OF SER AND ASSUMIR WITH OBJECT ZERO IN THE CONTEXT OF HOMOSEXUALITY
}

\begin{abstract}
We analyze the interpretation of verbal uses of "ser" and "assumir" as candidates of Forbidden-Object Constructions, when speakers use these transitive verbs in statements inserted in the discursive topic of homosexuality. Results enabled us to see the influence of interactional factors to the evaluation of transitivity in verbal uses.
\end{abstract}

KEYWORDS: transitivity; topic; homosexuality.

Recebido em 10/03/14 Aprovado em 25/08/14 


\section{ANEXO}

\section{Folder apresentado aos sujeitos}

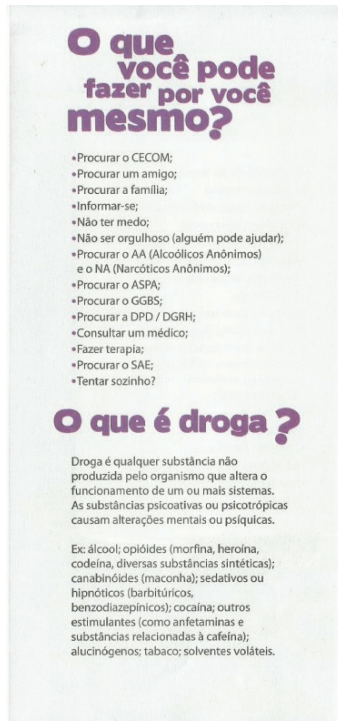

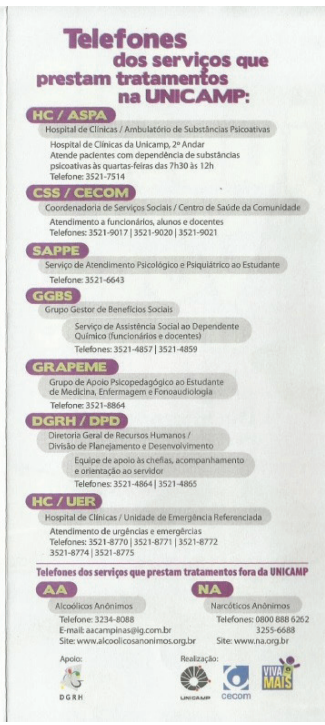

(CSS/UNICAMP)

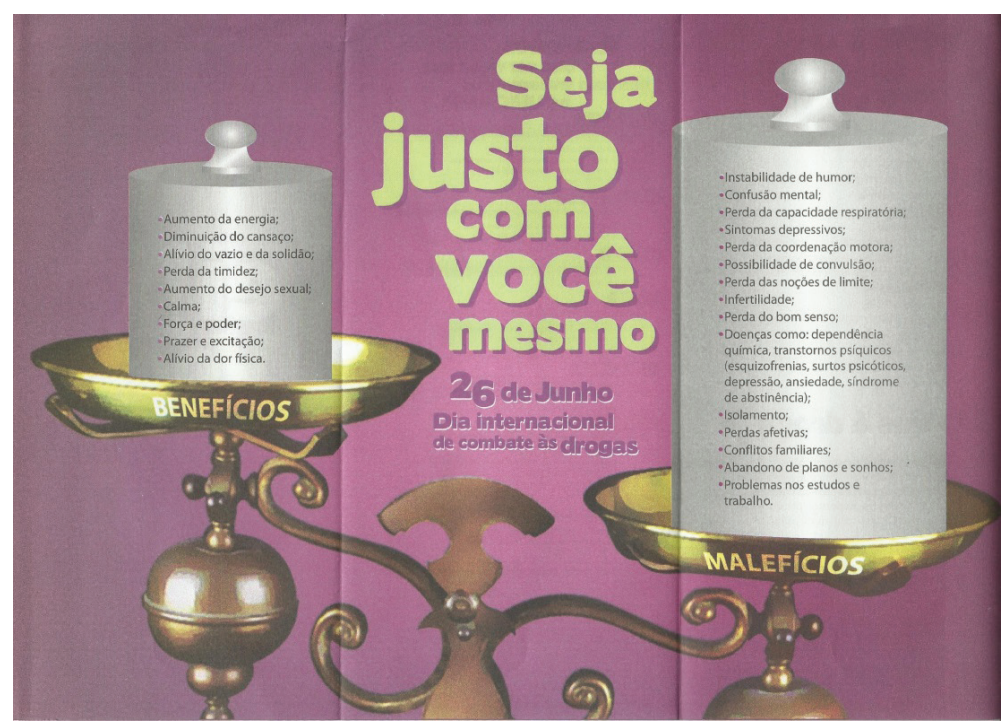

(CSS/UNICAMP) 